\title{
Hearing Loss and Physical Functioning Among Adults with Heart Failure: Data from NHANES
}

This article was published in the following Dove Press journal:

Clinical Interventions in Aging

\author{
Michael F Cosiano' \\ Deanna Jannat-Khah $\mathbb{D}^{2}$ \\ Frank R Lin ${ }^{3}$ \\ Parag Goyal ${ }^{2}$ \\ Michael McKee ${ }^{4}$ \\ Madeline R Sterling ${ }^{2}$ \\ 'Weill Cornell Medical College, Weill \\ Cornell Medicine, New York, NY, USA; \\ ${ }^{2}$ Department of Medicine, Weill Cornell \\ Medicine, New York, NY, USA; \\ ${ }^{3}$ Department of Otolaryngology - Head \& \\ Neck Surgery, Johns Hopkins University \\ School of Medicine, Baltimore, MD, USA; \\ ${ }^{4}$ Department of Family Medicine, \\ University of Michigan Medical School, \\ Ann Arbor, MI, USA
}

Correspondence: Madeline R Sterling Department of Medicine, Weill Cornell Medicine, New York, NY, USA

Tel + 1646-962-5029

Fax +1646-962-4610

Email mrs9012@med.cornell.edu

Twitter@mad_sters
Background: Hearing loss (HL) is associated with poor physical functioning among older adults, yet this association has not been examined in heart failure (HF), a disease in which both hearing loss and poor physical functioning are highly prevalent. We investigated whether this association exists in HF since HL represents a potentially modifiable risk factor for poor physical functioning.

Methods: We studied adults aged $\geq 70$ years with self-reported HF in the National Health and Nutrition Examination Survey (NHANES). HL was assessed and categorized using puretone averages. Activities of daily living (ADLs), instrumental ADLs (IADLs), leisure and social activities (LSA), lower extremity mobility (LEM), and general physical activity (GPA) were assessed. Multiple imputation was used to examine the association.

Results: One hundred eighty-one participants comprised our population. Those with $\geq$ moderate HL had more difficulty with ADLs (37.0\% vs $24.0 \%$, $\mathrm{p}=0.02)$, IADLs $(36.0 \%$ vs $23.0 \%, \mathrm{p}=0.05$ ), and LEM (37.3\% vs $20.0 \%, \mathrm{p}=0.009)$, compared to participants with none or mild HL. In multivariable models, $\geq$ moderate HL was significantly associated with difficulty in physical functioning across four of the five domains: ADLs: PR: 1.71 (95\% CI: 1.07-2.72); IADLs: PR: 1.71 (1.24-2.34); LEM: PR: 1.51 (1.01-2.26); and GPA: PR: 1.19 (1.00-1.41).

Conclusion: Among older adults with HF, moderate or greater HL was associated with a higher prevalence of difficulty with ADLs, IADLs, and LEM, compared to mild or no HL. Keywords: hearing loss, physical functioning, heart failure, prevalence

\section{Background}

Heart failure (HF) currently affects 6 million people in the United States, a number which is expected to rise as the population ages. ${ }^{1}$ Adults with HF often experience decreased quality of life (QOL), especially in domains of physical functioning and vitality. $^{2-6}$ Declining physical function may be related to the progression of HF, the aging process in general, or both. Poor physical functioning is associated with a variety of adverse outcomes including increased risk of falls, hospitalizations, morbidity, and mortality. ${ }^{7-10}$ Identifying modifiable risk factors for poor physical functioning in HF is important since targeted interventions have the potential to ameliorate these outcomes.

To date, only aerobic exercise has been shown to improve physical functioning among adults with HF. ${ }^{11,12}$ However, due to patients' severity of illness and symptoms, not all HF patients can fully engage in physical activity. ${ }^{13}$ One overlooked, but a potentially modifiable risk factor for poor physical functioning in $\mathrm{HF}$ is hearing loss. Hearing loss is associated with disability and poor physical 
functioning among older adults ${ }^{14-24}$ and has recently been shown to be highly prevalent among adults with $\mathrm{HF}^{25,26}$ Yet the association between hearing loss and poor physical functioning among adults with $\mathrm{HF}$ has not been investigated.

To address this gap, and guided by the conceptual framework of Lin and Albert, ${ }^{27}$ we used nationally representative data from the National Health and Nutrition Examination Survey (NHANES) to examine the association between hearing loss and physical functioning among older adults with HF.

\section{Methods}

\section{Study Cohort}

NHANES is an ongoing, cross-sectional study that assesses the health and nutritional status of the civilian noninstitutionalized US population. It utilizes a multistage probability sampling design such that national, populationlevel estimates can be derived. Conducted by the National Center of Health Statistics, NHANES obtains health and functional measures of participants through interviews and physical examinations continuously, releasing the collected data every 2 years. ${ }^{28}$ The study was approved by the National Center for Health Statistics institutional review board, and NHANES obtained written informed consent from all participants. Additionally, the IRB at Weill Cornell deemed this exempt.

In this study, we included data from the 2005-2006 and 2009-2010 waves since during these years, objective audiometric assessments were conducted among older adults. Our study sample was comprised of adults aged 70 and older who underwent audiometric assessment and had a self-reported HF history. Like previous NHANES studies, participants were considered to have HF if they ever answered yes to, "Has a doctor ever diagnosed you with heart failure?"29,30

\section{Audiometric Assessment}

Audiometric assessments were performed by a trained examiner according to the NHANES protocol. ${ }^{31}$ Briefly, air conduction hearing thresholds were assessed from both ears in a sound-isolating room in the NHANES mobile examination centers. Testing was done in accordance with the modified Hughson-Westlake test procedure using the automated testing mode of the audiometer (Interacoustics Model AD226) and/or manually per the testing protocol. Quality assurance and control were met through daily calibrations of equipment and monitoring of ambient noise level. A test-retest protocol at $1 \mathrm{kHz}$ threshold was used in order to ensure participant reliability. ${ }^{31}$ Hearing loss severity was defined according to a speech-frequency pure tone average (PTA) of thresholds at $0.5,1,2$, and 4 $\mathrm{kHz}$ in the better-hearing ear, using the World Health Organization's (WHO) guidelines. ${ }^{32}$ No hearing loss was defined as $25 \mathrm{~dB}$ or less; mild, 26-40 dB; moderate, 41-60 $\mathrm{dB}$; severe, $61-80 \mathrm{~dB}$; and profound, $81 \mathrm{~dB}$ or worse. ${ }^{32}$ Based on prior studies, and those which have examined the association between hearing loss and physical functioning, we further categorized hearing loss as none to mild versus moderate and greater. ${ }^{14-16,18,33-35}$

\section{Physical Functioning}

Physical functioning was assessed during the in-home interview using a Computer-Assisted Personal Interviewing system. Participants were asked about their ability to perform physical activities without the use of special equipment. Nineteen physical activities were assessed, subcategorized into five main domains: (1) activities of daily living (ADLs) (getting in and out of bed, eating, dressing yourself); (2) instrumental ADLs (IADLs) (managing money, performing house chores, preparing meals); (3) leisure and social activities (LSA) (going to the movies, attending social events, performing leisure activity at home); (4) lower extremity mobility (LEM) (walking a quarter mile, walking up to 10 steps, walking between rooms on the same floor); and (5) general physical activity (GPA) (lifting or carrying heavy objects, reaching up overhead, grasping/holding small objects, standing for long periods, sitting for long periods). The five physical functioning domains and the individual items which comprise them are summarized in Table 1. Participant responses were categorized as "no difficulty," "some difficulty," "much difficulty," or "unable to do." A limitation was considered as having some or more difficulty in one or more physical tasks in a given domain as previously described. ${ }^{36-40}$

\section{Covariates}

Demographic data included self-reported age, which we categorized as 70-79, 80+, gender $(\mathrm{M} / \mathrm{F})$, race/ethnicity, which we categorized as Non-Hispanic white, or NonHispanic black, Hispanic, education level categorized as $<$ high school, completed high school, and college, income, which we categorized as $<20,000, \geq 20,000$, and marital status which we categorized as married/living with a partner, or widowed/separated/divorced. 
Table I Five Physical Functioning Domains in NHANES

\begin{tabular}{|l|l|}
\hline $\begin{array}{l}\text { Physical Functioning } \\
\text { Domains }\end{array}$ & $\begin{array}{l}\text { Physical Tasks Comprising } \\
\text { Each Domain }\end{array}$ \\
\hline Activities of daily living (ADLs) & $\begin{array}{l}\text { Getting in and out of bed } \\
\text { Eating } \\
\text { Dressing yourself }\end{array}$ \\
\hline $\begin{array}{l}\text { Instrumental activities of daily } \\
\text { living (IADLs) }\end{array}$ & $\begin{array}{l}\text { Managing money } \\
\text { Performing house chores } \\
\text { Preparing meals }\end{array}$ \\
\hline Leisure and social activities & $\begin{array}{l}\text { Going to the movies } \\
\text { Attending social events } \\
\text { Performing leisure activity at home }\end{array}$ \\
\hline Lower extremity mobility (LEM) & $\begin{array}{l}\text { Walking one-quarter of a mile } \\
\text { Walking up I0 steps } \\
\text { Walking between rooms on the } \\
\text { same floor }\end{array}$ \\
\hline General physical activities (GPA) & $\begin{array}{l}\text { Lifting or carrying heavy objects } \\
\text { Reaching up overhead } \\
\text { Grasping/holding small objects } \\
\text { Standing for long periods }\end{array}$ \\
\hline
\end{tabular}

Participants were classified as having coronary heart disease (CHD) if they had a self-reported previous diagnosis of CHD, or if they reported a history of angina or myocardial infarction. The presence of diabetes was determined if participants had a self-reported previous diagnosis of diabetes, if they were taking medication for diabetes, if they had a 2-hrs fasting glucose concentration of $126 \mathrm{mg} / \mathrm{dL}$ or greater, or if they had a hemoglobin a1c of $6.5 \%$ or greater. Participants were classified as having hypertension if they reported a history of high blood pressure, were taking a prescription medication for high blood pressure or, if during the examination in the MEC, the mean of four blood pressure measurements was more than $140 \mathrm{mmHg}$ (systolic) or more than $90 \mathrm{mmHg}$ (diastolic). Stroke history was ascertained by self-report of a physician diagnosis. Finally, smoking history was categorized as never/former or current.

\section{Statistical Analysis}

NHANES examination weights were used to determine national estimates. ${ }^{28}$ Differences between participant characteristics by HF status were determined with Chi-square tests for categorical variables and t-tests for continuous variables. The association between hearing loss severity and the physical functioning outcomes was determined using multiple imputation to adjust for demographic and other clinical covariates. For all models, prevalence ratios (PRs) and their corresponding 95\% confidence intervals (CIs) were calculated. Associations were considered to be statistically significant at $\mathrm{p}<0.05$. STATA procedures for complex survey design were used for all analyses (StataCorp LP, College Station, TX).

\section{Results}

Overall, 1972 participants 70 years of age and older underwent audiometric assessment in the 2005-2006 and 2009-2010 waves of NHANES. Of these, the 181 who had HF comprised our study sample. The prevalence of hearing loss was high, with 39.4\% (95\% CI, 31.8-47.6) having mild hearing loss and 39.0\% (95\% CI, 31.0-47.7) having moderate or greater hearing loss.

The characteristics of HF participants by hearing loss severity are shown in Table 2. Overall, 48.8\% (95\% CI, 38.7-59.0) were 80 years or older, 53.3\% (95\% CI, 46.5-60.0) were female, and 85.0\% (95\% CI, 79.0-89.5) were non-Hispanic White. The overall prevalence of cardiovascular risk factors was high; a total of 58.0\% $(95 \%$ CI, 48.5-66.9) of participants had CHD and 70.6\% (95\% CI, 63.0-77.2) had hypertension. Compared to those with none or mild hearing loss, participants with moderate or greater hearing loss were older, less educated, of lower socioeconomic status, and were more often widowed, divorced or separated. In terms of cardiovascular risk factors, CHD was more prevalent among those with moderate or greater hearing loss.

Participants with moderate or greater hearing loss had significantly more difficulty with ADLs $(37.0 \%$ vs $24.0 \%$, $\mathrm{p}=0.02)$, IADLs $(36.0 \%$ vs $23.0 \%, \mathrm{p}=0.05)$, and LEM (37.0\% vs $20.0 \%, p=0.009$ ), compared to those with less severe hearing loss (Table 3 ).

Table 4 shows the associations between the severity of hearing loss and the five physical functioning outcomes. In unadjusted models, moderate or greater hearing loss was associated with a significantly higher prevalence of difficulty in physical functioning across four of the five domains: ADLs (PR, 1.82; 95\% CI, 1.13-2.93), IADLs (PR, 1.56; 95\% CI, 1.09-2.22), LEM (PR, 1.39; 95\% CI, 1.08-1.80), and GPA (PR, 1.19; 95\% CI, 1.02-1.38) (Table 4, Model 1). An association between moderate or greater hearing loss and difficulty with LSA was also seen (PR, 1.35; 95\% CI, 0.97-1.88); however, it did not reach statistical significance. 
Table 2 Characteristics of the Heart Failure Population from the 2005-2006 and 2009-2010 National Health and Nutrition Examination Survey (NHANES) a , by Hearing Loss Severity

\begin{tabular}{|c|c|c|c|}
\hline \multirow[t]{2}{*}{ Characteristics } & \multicolumn{3}{|c|}{ Prevalence \% (95\% Confidence Interval) } \\
\hline & Overall $^{\mathbf{b}}$ & None/Mild & Moderate or Greater \\
\hline \multicolumn{4}{|l|}{ Age group, years } \\
\hline 70-79 & $51.2(41.0-61.3)$ & $70.2(55.4-81.8)$ & $30.1(15.8-49.6)$ \\
\hline $80+$ & $48.8(38.7-59.0)$ & $29.8(18.3-44.6)$ & $69.9(50.4-84.2)$ \\
\hline \multicolumn{4}{|l|}{ Gender } \\
\hline Male & $46.7(40.0-53.5)$ & $47.6(37.9-57.5)$ & $46.9(34.3-59.8)$ \\
\hline Female & $53.3(46.5-60.0)$ & $52.4(42.5-62.1)$ & $53.1(40.2-65.7)$ \\
\hline \multicolumn{4}{|l|}{ Race/ethnicity } \\
\hline Hispanic & $4.8(2.1-9.2)$ & $7.1(3.3-14.9)$ & $0.80(0.1-6.0)$ \\
\hline Non-Hispanic white & $85.0(79.0-89.5)$ & $80.4(71.1-87.3)$ & $96.3(89.3-98.8)$ \\
\hline Non-Hispanic black & $10.2(7.0-14.9)$ & $12.5(7.5-19.9)$ & $2.9(0.8-9.9)$ \\
\hline \multicolumn{4}{|l|}{ Education Level } \\
\hline$<$ High school & $30.9(24.9-37.7)$ & $26.6(18.4-36.9)$ & $35.4(22.6-50.6)$ \\
\hline High school & $33.2(25.4-42.0)$ & $39.3(28.3-51.5)$ & $34.7(22.4-49.5)$ \\
\hline College or higher & $35.9(26.5-46.6)$ & $34.1(23.2-46.9)$ & $30.0(18.6-44.6)$ \\
\hline \multicolumn{4}{|l|}{ Income } \\
\hline$\geq 20,000$ & $70.8(63.6-77.0)$ & $75.0(63.7-83.8)$ & $67.5(50.8-80.7)$ \\
\hline$<20,000$ & $29.2(23.0-36.4)$ & $25.0(16.3-36.3)$ & $32.5(19.3-49.2)$ \\
\hline \multicolumn{4}{|l|}{ Marital Status } \\
\hline Married/living with partner & $50.3(38.5-62.1)$ & $64.1(50.2-76.0)$ & $37.1(20.3-57.7)$ \\
\hline Widowed, separated, or divorced & $49.7(37.9-61.6)$ & $35.9(24.0-49.8)$ & $62.9(42.3-79.7)$ \\
\hline Coronary heart disease & $58.0(48.5-66.9)$ & $53.3(36.8-69.1)$ & $65.6(48.7-79.3)$ \\
\hline Diabetes & $39.7(31.6-48.4)$ & $46.0(32.1-60.6)$ & $36.5(25.7-48.8)$ \\
\hline Hypertension & $70.6(63.0-77.2)$ & $75.5(64.2-84.1)$ & $68.0(54.6-79.0)$ \\
\hline Stroke & $24.7(17.0-34.3)$ & $25.7(\mid 4.9-40.5)$ & $22.0(I 5.1-30.8)$ \\
\hline \multicolumn{4}{|l|}{ Smoking Status } \\
\hline Never/former & $91.8(86.1-95.3)$ & $88.3(79.3-93.7)$ & $97.2(91.2-99.1)$ \\
\hline Current & $8.2(4.7-13.9)$ & II.7 (6.3-20.7) & $2.8(0.9-8.8)$ \\
\hline
\end{tabular}

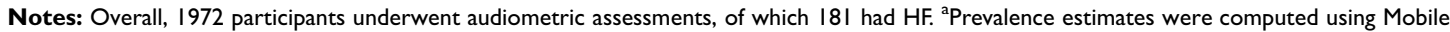
Examination Center examination weights to provide estimates for the total US population and are age standardized to the US 2010 Census population. ' Missing data included: level of education ( $0.50 \%)$, income $(3.35 \%)$, marital status $(0.2 \%)$, $\mathrm{CHD}(0.66 \%)$, hypertension $(0.35 \%)$, smoking (48.5\%), stroke (0.41\%).

Abbreviation: PTAR, pure tone audiometry range.

After adjustment for age, socio-demographic characteristics, and clinical comorbidities, the association between hearing loss severity and difficulty in physical functioning remained significant (Table 4, Model 3). In this fully adjusted model, moderate or greater hearing loss was associated with a significantly higher prevalence of difficulty with ADLs (aPR, 1.78; 95\% CI, 1.07-2.94), IADLs (aPR, 1.91; 95\% CI, 1.34-2.73), LSA (aPR, 1.52; 95\% CI, 1.01-2.30), LEM (aPR, 1.58; 95\% CI, 1.16-2.13), and GPA (aPR, 1.22; 95\% CI, 1.04-1.42). In this fully adjusted model, no participant characteristics were independently associated with difficulty in physical functioning across the domains.

\section{Discussion}

In this nationally representative study of older adults with HF, we found that hearing loss severity was associated with greater difficulty with physical functioning in the following domains including activities of daily living (ADLs), instrumental ADLs, leisure and social activity (LSA), lower extremity mobility (LEM), and general physical activity (GPA). These associations 
Table 3 Hearing Loss Severity and Difficulty with Physical Functioning Domains Among Participants with Heart Failure

\begin{tabular}{|c|c|c|c|c|}
\hline \multicolumn{2}{|c|}{ Hearing Loss (HL) } & \multicolumn{3}{|c|}{ Difficulty with Physical Functioning } \\
\hline & & No $(\mathbf{N}, \%)$ & Yes (N, \%) & P-value \\
\hline \multicolumn{2}{|c|}{ Activities of daily living (ADLs) } & 94 & 86 & \\
\hline \multicolumn{2}{|l|}{ Mean (SD) } & $36.7(14.2)$ & $42.1(15.3)$ & 0.03 \\
\hline \multirow[t]{3}{*}{ Severity of HL } & None & $18(19 \%)$ & $9(10 \%)$ & 0.02 \\
\hline & Mild & $38(40 \%)$ & $20(23 \%)$ & \\
\hline & Moderate/Severe/Profound & $23(24 \%)$ & $32(37 \%)$ & \\
\hline \multicolumn{2}{|c|}{ Instrumental ADLs (IADLs) } & 75 & 99 & \\
\hline \multicolumn{2}{|l|}{ Mean (SD) } & $36.9(15.3)$ & $40.4(14.1)$ & 0.17 \\
\hline \multirow[t]{3}{*}{ Severity of $\mathrm{HL}$} & None & I 4 (19\%) & $13(13 \%)$ & 0.05 \\
\hline & Mild & 31 (4I\%) & $26(26 \%)$ & \\
\hline & Moderate/Severe/Profound & 17 (23\%) & $36(36 \%)$ & \\
\hline \multicolumn{2}{|c|}{ Lower extremity mobility (LEM) } & 70 & 110 & \\
\hline \multicolumn{2}{|l|}{ Mean (SD) } & $36.8(13.4)$ & $40.5(15.6)$ & 0.15 \\
\hline \multirow[t]{3}{*}{ Severity of $\mathrm{HL}$} & None & $10(14 \%)$ & $17(15 \%)$ & 0.009 \\
\hline & Mild & 31 (44\%) & $27(24 \%)$ & \\
\hline & Moderate/Severe/Profound & I4 (20\%) & 41 (37\%) & \\
\hline \multicolumn{2}{|c|}{ Leisure and social activities (LSA) } & 91 & 89 & \\
\hline \multicolumn{2}{|l|}{ Mean (SD) } & $37.7(14.8)$ & $40.6(14.9)$ & 0.24 \\
\hline \multirow[t]{3}{*}{ Severity of HL } & None & $18(20 \%)$ & $9(10 \%)$ & 0.19 \\
\hline & Mild & 31 (34\%) & $27(30 \%)$ & \\
\hline & Moderate/Severe/Profound & $25(27 \%)$ & $30(34 \%)$ & \\
\hline \multicolumn{2}{|c|}{ General physical activities (GPA) } & 34 & 146 & \\
\hline \multicolumn{2}{|l|}{ Mean (SD) } & 37.9 (13.9) & $39.4(15.1)$ & 0.63 \\
\hline \multirow[t]{3}{*}{ Severity of $\mathrm{HL}$} & None & $5(14.7 \%)$ & $22(15.1 \%)$ & 0.09 \\
\hline & Mild & $17(50.0 \%)$ & $4 \mathrm{I}(28.1 \%)$ & \\
\hline & Moderate/Severe/Profound & 7 (20.6\%) & 48 (32.9\%) & \\
\hline
\end{tabular}

Notes: Hearing loss was defined by pure tone audiometric range (PTAR). Difficulty (yes/no) in physical domain defines as a response of some difficulty or more in at least one of the physical task questions within a domain. Missing hearing data per physical functioning domain: ADLs (22.1\%), Instrumental ADLs (20.4\%), LEM (22.1\%), Leisure and Social (22.1\%), General Physical Activities (22.1\%).

Abbreviation: SD, standard deviation.

persisted after adjustment for age, demographics, and clinical variables.

While the association between hearing loss and poor physical functioning has been established among older adults and older adults with cardiovascular disease (CVD) and CVD risk factors, ${ }^{16-26,41,42}$ this study is the first to investigate this association in $\mathrm{HF}$, a chronic disease characterized by high prevalence of physical, cognitive, and sensory deficits. ${ }^{2-4,6,43-45}$ This association, however, may be of particular importance in HF. A recent study by Gorodeski et al (2018) recommends that older adults with
HF be cared for using a domain framework that includes regular assessment of medical issues, mind and emotion, physical function, and social environment. ${ }^{5}$ This work posits that HF patients have many geriatric conditions that require screening and treatment. For example, physical functioning assessments should encompass a review of ADLs/IADLS, gait speed, and frailty to determine patients' risk for falls, hospitalizations, and mortality. ${ }^{7-10}$ Our findings add to this framework by suggesting that hearing loss be considered in the care of HF patients, and in particular, those with poor physical functioning. 
Table 4 Association Between Severity of Hearing Loss and Difficulty in Physical Functioning Among Adults with HF Using Multiple Imputation

\begin{tabular}{|l|l|l|l|}
\hline Physical Functioning Domain & Model I & Model 2 & Model 3 \\
\cline { 2 - 4 } & PR [95\% CI] & PR [95\% CI] & PR [95\% CI] \\
\hline Activities of daily living (ADLs) & $1.82[1.13,2.93]$ & $1.74[1.18,2.57]$ & $1.71[1.07,2.72]$ \\
Instrumental ADLs (IADLs) & $1.56[1.09,2.23]$ & $1.64[1.26,2.15]$ & $1.71[1.24,2.34]$ \\
Leisure and social activities & $1.35[0.97,1.88]$ & $1.47[1.01,2.14]$ & $1.51[1.01,2.26]$ \\
Lower extremity mobility & $1.39[1.08,1.80]$ & $1.49[1.10,2.02]$ & $1.50[1.11,2.03]$ \\
General physical activities & $1.19[1.02,1.38]$ & $1.17[0.98,1.39]$ & $1.19[1.00,1.41]$ \\
\hline
\end{tabular}

Notes: Model I - Crude. Model 2 - Demographics (Age, Race, Gender, Education, Income, Marital Status). Model 3 - Model 2 + Coronary heart disease, stroke, diabetes, hypertension, smoking.

Abbreviations: $\mathrm{PR}$, prevalence ratio; $\mathrm{Cl}$, confidence interval.

While the underlying mechanism between hearing loss and physical functioning is not well understood in HF, several possible explanations exist. First, individuals with HF share many CVD risk factors that are associated with hearing loss, including hypertension, CHD, diabetes, and smoking. ${ }^{46-52} \mathrm{CVD}$ and its risk factors cause microvascular ischemia leading to ciliary damage that results in hearing loss as well as poor health and function. ${ }^{49,50,53,54}$ The common location of cochlear and vestibular function in conjunction with concurrent neuronal degeneration, given cardiovascular risk factors such as diabetes, could explain the association between hearing loss and physical function as the balance is crucial for physical functioning. ${ }^{55}$ Secondly, ototoxic medications such as loop diuretics and aspirin are commonly used in HF patients and could contribute to hearing loss. Third, it has been suggested that hearing loss could also worsen physical functioning through increased cognitive load and decreased executive function. ${ }^{56,57}$ Thus, less cognitive reserve may remain for gait and balance which directly impact physical functioning. ${ }^{58-61}$ Finally, hearing loss often results in communication barriers which have been shown to increase the risk of social isolation. ${ }^{18,62,63}$ Social isolation affects health care and social communication, impacting an individual's ability to do physical activities and manage their health conditions effectively. Given the cross-sectional nature of this study, additional prospective research is needed to better elucidate the underlying pathway.

Beyond additional research in this area, our findings suggest that increased awareness of hearing loss among HF patients and its possible deleterious on physical functioning is warranted. Among those with established or worsening physical functioning, inpatient and outpatient healthcare providers might consider screening HF patients for hearing deficits during medical encounters. Second, among those with suspected hearing loss, referral to an audiologist and otolaryngologist may be appropriate. Finally, since effective strategies exist which can mitigate the effects of hearing loss, providers ought to familiarize themselves with hearing aid options and refer patients when appropriate.

\section{Strengths and Limitations}

Our study has several strengths. First, we use a comprehensive battery of physical functioning domains which have been well accepted in the literature. ${ }^{36-40}$ Second, NHANES is a nationally representative cohort that utilizes objective audiometric assessments and a standard definition of hearing loss according to the World Health Organization's (WHO) guidelines. ${ }^{32} \mathrm{We}$ also note a few limitations. Although we found a strong association between hearing loss severity and poor physical functioning in HF, casual inferences cannot be made. Additionally, NHANES is a nationally representative cohort of the US population, it does not include adults who reside in nursing homes or rehab centers, which are relevant to HF patients. Lastly, although our study used objective audiometric data, HF status and physical functioning data were obtained through self-report.

\section{Conclusion}

Our findings suggest that hearing loss severity among older adults with HF is associated with a higher prevalence of difficulty in physical functioning across several domains. Increased awareness of this association is needed among healthcare providers. Additional observational research is needed to further investigate the association and underlying mechanism between hearing loss and physical functioning in HF. If an association between hearing loss and physical 
functioning among adults with HF existed, interventions to mitigate hearing loss may be warranted.

\section{Abbreviations}

HL, Hearing loss; HF, Heart failure; NHANES, National Health and Nutrition Examination Survey; ADLs, Activities of daily living; IADLs, Instrumental ADLs; LSA, Leisure and social activities; LEM, Lower extremity mobility; GPA, General physical activity; CHD, Coronary heart disease; CVD, Cardiovascular disease.

\section{Impact Statement}

We certify that this work is novel clinical research. The association between hearing loss and physical functioning among adults with heart failure and has not previously been investigated.

\section{Acknowledgments}

We thank all of the NHANES participants without whom this study would not be possible.

\section{Disclosure}

Dr. Goyal received research support from Amgen, unrelated to the content of this manuscript. Dr. Lin is a consultant to Amplifon, Cochlear Ltd., and Boehringer Ingelheim, unrelated to the content of this manuscript. He also reports grants from the National Institutes of Health and Eleanor Schwartz Charitable Foundation, during the conduct of the study; personal fees from Cochlear Ltd., Amplifon, and Boehringer Ingelheim, outside the submitted work. The authors report no other conflicts of interest in this work.

\section{References}

1. Benjamin Emelia J, Virani Salim S, Callaway Clifton W, et al. Heart disease and stroke statistics—2018 update: a report from the American Heart Association. Circulation. 2018;137(12):e67-e492. doi:10.1161/ CIR.0000000000000558

2. Murad K, Kitzman DW. Frailty and multiple comorbidities in the elderly patient with heart failure: implications for management. Heart Fail Rev. 2012;17(4-5):581-588. doi:10.1007/s10741-0119258-y

3. Forman DE, Arena R, Boxer R, et al. Prioritizing functional capacity as a principal end point for therapies oriented to older adults with cardiovascular disease: a scientific statement for Healthcare Professionals from the American Heart Association. Circulation. 2017;135(16):e894-e918. doi:10.1161/CIR.0000000000000483

4. Warraich Haider J, Kitzman Dalane W, Whellan David J, et al. Physical function, frailty, cognition, depression, and quality of life in hospitalized adults $\geq 60$ years with acute decompensated heart failure with preserved versus reduced ejection fraction. Circ Heart Fail. 2018;11(11):e005254.
5. Gorodeski EZ, Goyal P, Hummel SL, et al. Domain management approach to heart failure in the geriatric patient. Present Fut. 2018;71 (17):1921-1936.

6. Lewis Eldrin F. Still at the drawing board. Circ Heart Fail. 2012;5 (2):137-139. doi:10.1161/CIRCHEARTFAILURE.112.966861

7. Hegde SM, Claggett B, Shah AM, et al. Physical activity and prognosis in the TOPCAT trial (Treatment of Preserved Cardiac Function Heart Failure With an Aldosterone Antagonist). Circulation. 2017;136(11):982-992. doi:10.1161/CIRCULATIONAHA.117.028 002

8. Hornsby WE, Sareini M-A, Golbus JR, et al. Lower extremity function is independently associated with hospitalization burden in heart failure with preserved ejection fraction. J Card Fail. 2019;25(1):2-9. doi:10.1016/j.cardfail.2018.09.002

9. Manemann SMC, Chamberlain AM, Boyd CM, et al. Fall risk and outcomes among patients hospitalized with cardiovascular disease in the community. Circ Cardiovasc Qual Outcomes. 2018;11(8): e004199.

10. Murad K, Goff DC Jr., Morgan TM, et al. Burden of comorbidities and functional and cognitive impairments in elderly patients at the initial diagnosis of heart failure and their impact on total mortality: the cardiovascular health study. JACC Heart Fail. 2015;3(7):54 2-550. doi:10.1016/j.jchf.2015.03.004

11. Ostman C, Jewiss D, Smart NA. The effect of exercise training intensity on quality of life in heart failure patients: a systematic review and meta-analysis. Cardiology. 2017;136(2):79-89. doi:10.1 $159 / 000448088$

12. Fleg JL. Exercise therapy for older heart failure patients. Heart Fail Clin. 2017;13(3):607-617. doi:10.1016/j.hfc.2017.02.012

13. O'Connor CM, Whellan DJ, Lee KL, et al. Efficacy and safety of exercise training in patients with chronic heart failure: HF-ACTION randomized controlled trial. JAMA. 2009;301(14):1439-1450. doi:10. 1001/jama.2009.454

14. Chen DS, Betz J, Yaffe K, et al. Association of hearing impairment with declines in physical functioning and the risk of disability in older adults. J Gerontol A Biol Sci Med Sci. 2015;70(5):654-661. doi:10.1093/gerona/glu207

15. Chen DS, Genther DJ, Betz J, Lin FR. Association between hearing impairment and self-reported difficulty in physical functioning. $J \mathrm{Am}$ Geriatr Soc. 2014;62(5):850-856. doi:10.1111/jgs.12800

16. Gopinath B, Schneider J, McMahon CM, Teber E, Leeder SR, Mitchell P. Severity of age-related hearing loss is associated with impaired activities of daily living. Age Ageing. 2012;41(2):195-200. doi:10.1093/ageing/afr155

17. Mikkola TM, Polku H, Portegijs E, Rantakokko M, Rantanen T, Viljanen A. Self-reported hearing status is associated with lower limb physical performance, perceived mobility, and activities of daily living in older community-dwelling men and women. $J \mathrm{Am}$ Geriatr Soc. 2015;63(6):1164-1169. doi:10.1111/jgs.13381

18. Strawbridge WJ, Wallhagen MI, Shema SJ, Kaplan GA. Negative consequences of hearing impairment in old age: a longitudinal analysis. Gerontologist. 2000;40(3):320-326. doi:10.1093/geront/ 40.3.320

19. Viljanen A, Kaprio J, Pyykko I, Sorri M, Koskenvuo M, Rantanen T. Hearing acuity as a predictor of walking difficulties in older women. $J$ Am Geriatr Soc. 2009;57(12):2282-2286. doi:10.1111/j.15325415.2009.02553.x

20. Bess FH, Lichtenstein MJ, Logan SA, Burger MC, Nelson E. Hearing impairment as a determinant of function in the elderly. J Am Geriatr Soc. 1989;37(2):123-128. doi:10.1111/j.1532-5415. 1989.tb05870.x

21. Dargent-Molina P, Hays M, Breart G. Sensory impairments and physical disability in aged women living at home. Int J Epidemiol. 1996;25(3):621-629. doi:10.1093/ije/25.3.621

22. Keller BK, Morton JL, Thomas VS, Potter JF. The effect of visual and hearing impairments on functional status. $J$ Am Geriatr Soc. 1999;47(11):1319-1325. doi:10.1111/j.1532-5415.1999.tb07432.x 
23. Chia EM, Wang JJ, Rochtchina E, Cumming RR, Newall P, Mitchell P. Hearing impairment and health-related quality of life: the Blue Mountains Hearing Study. Ear Hear. 2007;28(2):187-195. doi:10.1097/AUD.0b013e31803126b6

24. Reuben DB, Mui S, Damesyn M, Moore AA, Greendale GA. The prognostic value of sensory impairment in older persons. $J \mathrm{Am}$ Geriatr Soc. 1999;47(8):930-935. doi:10.1111/j.1532-5415.1999. tb01286.x

25. Lin FR, Thorpe R, Gordon-Salant S, Ferrucci L. Hearing loss prevalence and risk factors among older adults in the United States. J Gerontol A Biol Sci Med Sci. 2011;66(5):582-590. doi:10.1093/ gerona/glr002

26. Agrawal Y, Platz EA, Niparko JK. Prevalence of hearing loss and differences by demographic characteristics among US adults: data from the National Health and Nutrition Examination Survey, 1999-2004. Arch Intern Med. 2008;168(14):1522-1530. doi:10.10 01/archinte.168.14.1522

27. Lin FR, Albert M. Hearing loss and dementia - who is listening? Aging Ment Health. 2014;18(6):671-673. doi:10.1080/13607863. 2014.915924

28. Johnson C, Paulose-Ram R, Ogden CL, et al. National Health and Nutrition Examination Survey: analytic guidelines, 1999-2010. National Center for Health Statistics. Vital Health Stat. 2013;2 (161).

29. Lemon SC, Olendzki B, Magner R, et al. The dietary quality of persons with heart failure in NHANES 1999-2006. J Gen Intern Med. 2010;25(2):135-140. doi:10.1007/s11606-009-1139-x

30. Lama Tamang TG, Tang L, Chuang J, Patel RJ, Wong ND. Examining risk factor goal attainment and adherence to treatment among US heart failure patients: the National Health and Nutrition Examination Survey 2007-2010. Am J Cardiovasc Drugs. 2014;14 (1):41-49. doi:10.1007/s40256-013-0046-z

31. Centers for Disease Control and Prevention. National Centers for Health Statistics. The National Health and Nutrition Examination Survey. Audiometry manual 2005-2006; 2010. Available from: http://www.cdc.gov/nchs/data/nhanes/nhanes_05_06/AU.pdf. Accessed June 19, 2018.

32. World Health Organization Prevention of Blindness and Deafness (PBD) Program. Prevention of Deafness and Hearing Impaired Grades of Hearing Impairment. Available from: http://www.who.int/ pbd/deafness/hearing_impairment_grades/en/index.html. Accessed June 19, 2018.

33. Gispen FE, Chen DS, Genther DJ, Lin FR. Association between hearing impairment and lower levels of physical activity in older adults. J Am Geriatr Soc. 2014;62(8):1427-1433. doi:10.1111/ jgs. 12938

34. Scinicariello F, Przybyla J, Carroll Y, Eichwald J, Decker J, Breysse PN. Age and sex differences in hearing loss association with depressive symptoms: analyses of NHANES 2011-2012. Psychol Med. 2018;1-7.

35. Jung DJ, Lee JH, Kim T, Kim H-G, Lee JY, Lee K-Y. Association between hearing impairment and albuminuria with or without diabetes mellitus. Clin Exp Otorhinolaryngol. 2017;10(3):221-227. doi:10.21053/ceo.2016.00787

36. Kuo HK, Leveille SG, Yu YH, Milberg WP. Cognitive function, habitual gait speed, and late-life disability in the National Health and Nutrition Examination Survey (NHANES) 1999-2002. Gerontology. 2007;53(2):102-110. doi:10.1159/000096792

37. Kalyani RR, Saudek CD, Brancati FL, Selvin E. Association of diabetes, comorbidities, and $\mathrm{A} 1 \mathrm{C}$ with functional disability in older adults: results from the National Health and Nutrition Examination Survey (NHANES), 1999-2006. Diabetes Care. 2010;33(5):10 55-1060. doi:10.2337/dc09-1597

38. Wu LW, Chen WL, Peng TC, et al. All-cause mortality risk in elderly individuals with disabilities: a retrospective observational study. $B M J$ Open. 2016;6(9):e011164. doi:10.1136/bmjopen-2016-011164
39. Kao TW, Chou CH, Wang CC, Chou CC, Hu J, Chen WL. Associations between serum total bilirubin levels and functional dependence in the elderly. Intern Med J. 2012;42(11):1199-1207. doi:10.1111/j.1445-5994.2011.02620.x

40. Plantinga LC, Johansen K, Crews DC, et al. Association of CKD with disability in the United States. Am J Kidney Dis. 2011;57 (2):212-227. doi:10.1053/j.ajkd.2010.08.016

41. Loprinzi PD, Gilham B, Cardinal BJ. Association between accelerometer-assessed physical activity and objectively measured hearing sensitivity among U.S. adults with diabetes. Res $Q$ Exerc Sport. 2014;85(3):390-397. doi:10.1080/02701367.2014.930404

42. Quinones PA, Seidl H, Holle R, et al. New potential determinants of disability in aged persons with myocardial infarction: results from the KORINNA-study. BMC Geriatr. 2014;14:34. doi:10.1186/14712318-14-34

43. Cannon JA, Moffitt P, Perez-Moreno AC, et al. Cognitive impairment and heart failure: systematic review and meta-analysis. $J$ Card Fail. 2017;23(6):464-475. doi:10.1016/j.cardfail.2017.04.007

44. Sterling MR, Lin FR, Jannat-Khah DP, Goman AM, Echeverria SE, Safford MM. Hearing Loss Among Older Adults With Heart Failure in the United States: data From the National Health and Nutrition Examination Survey. JAMA Otolaryngol Head Neck Surg. 2018;144 (3):273. doi:10.1001/jamaoto.2017.2979

45. Sterling MR, Jannat-Khah D, Vitale S, Safford MM. Can your patients with heart failure see? The prevalence of visual impairment among adults with heart failure. J Gen Intern Med. 2018;33 (5):605-607. doi:10.1007/s11606-018-4366-1

46. Agrawal Y, Platz EA, Niparko JK. Risk factors for hearing loss in US adults: data from the National Health and Nutrition Examination Survey, 1999 to 2002. Otol Neurotol. 2009;30(2):139-145. doi:10.1097/MAO.0b013e318192483c

47. Helzner EP, Patel AS, Pratt S, et al. Hearing sensitivity in older adults: associations with cardiovascular risk factors in the health, aging and body composition study. J Am Geriatr Soc. 2011;59 (6):972-979. doi:10.1111/j.1532-5415.2011.03444.x

48. Cruickshanks KJ, Nondahl DM, Dalton DS, et al. Smoking, central adiposity, and poor glycemic control increase risk of hearing impairment. J Am Geriatr Soc. 2015;63(5):918-924. doi:10.1111/ jgs. 13401

49. Gates GA, Cobb JL, D'Agostino RB, Wolf PA. The relation of hearing in the elderly to the presence of cardiovascular disease and cardiovascular risk factors. Arch Otolaryngol Head Neck Surg. 1993;119(2):156-161. doi:10.1001/archotol.1993.01880140038006

50. Torre P 3rd, Cruickshanks KJ, Klein BE, Klein R, Nondahl DM. The association between cardiovascular disease and cochlear function in older adults. J Speech Lang Hear Res. 2005;48(2):473-481. doi:10. 1044/1092-4388(2005/032)

51. Dalton DS, Cruickshanks KJ, Klein R, Klein BE, Wiley TL. Association of NIDDM and hearing loss. Diabetes Care. 1998;21 (9):1540-1544. doi:10.2337/diacare.21.9.1540

52. Cruickshanks KJ, Klein R, Klein BE, Wiley TL, Nondahl DM, Tweed TS. Cigarette smoking and hearing loss: the epidemiology of hearing loss study. JAMA. 1998;279(21):1715-1719. doi:10.1001/ jama.279.21.1715

53. Friedland DR, Cederberg C, Tarima S. Audiometric pattern as a predictor of cardiovascular status: development of a model for assessment of risk. Laryngoscope. 2009;119(3):473-486. doi:10.10 02/lary.20130

54. Seidman MD, Quirk WS, Shirwany NA. Mechanisms of alterations in the microcirculation of the cochlea. Ann $N$ Y Acad Sci. 1999;884:226-232. doi:10.1111/j.1749-6632.1999.tb08644.x

55. Agrawal Y, Carey JP, Della Santina CC, Schubert MC, Minor LB. Disorders of balance and vestibular function in US adults: data from the National Health and Nutrition Examination Survey, 2001-2004. Arch Intern Med. 2009;169(10):938-944. doi:10.1001/archinternmed. 2009.66 
56. Tun PA, McCoy S, Wingfield A. Aging, hearing acuity, and the attentional costs of effortful listening. Psychol Aging. 2009;24 (3):761-766. doi:10.1037/a0014802

57. Wingfield A, Tun PA, McCoy SL. Hearing loss in older adulthood: what it is and how it interacts with cognitive performance. Curr Dir Psychol Sci. 2005;14(3):144-148. doi:10.1111/j.0963-7214.2005.00 356.x

58. Woollacott M, Shumway-Cook A. Attention and the control of posture and gait: a review of an emerging area of research. Gait Posture. 2002;16(1):1-14. doi:10.1016/S0966-6362(01)00156-4

59. Watson NL, Rosano C, Boudreau RM, et al. Executive function, memory, and gait speed decline in well-functioning older adults. J Gerontol A Biol Sci Med Sci. 2010;65A(10):1093-1100. doi:10. 1093/gerona/glq111
60. Shumway-Cook A, Woollacott M. Attentional demands and postural control: the effect of sensory context. J Gerontol A Biol Sci Med Sci. 2000;55(1):M10-M16.

61. Atkinson HH, Rosano C, Simonsick EM, et al. Cognitive function, gait speed decline, and comorbidities: the health, aging and body composition study. J Gerontol A Biol Sci Med Sci. 2007;62 (8):844-850. doi:10.1093/gerona/62.8.844

62. Mick P, Kawachi I, Lin FR. The association between hearing loss and social isolation in older adults. Otolaryngol Head Neck Surg. 2014;150(3):378-384. doi:10.1177/0194599813518021

63. Mulrow CD, Aguilar C, Endicott JE, et al. Association between hearing impairment and the quality of life of elderly individuals. J Am Geriatr Soc. 1990;38(1):45-50. doi:10.1111/j.1532-5415.1990. tb01595.x
Clinical Interventions in Aging

\section{Publish your work in this journal}

Clinical Interventions in Aging is an international, peer-reviewed journal focusing on evidence-based reports on the value or lack thereof of treatments intended to prevent or delay the onset of maladaptive correlates of aging in human beings. This journal is indexed on PubMed Central, MedLine, CAS, Scopus and the Elsevier
Dovepress

Bibliographic databases. The manuscript management system is completely online and includes a very quick and fair peer-review system, which is all easy to use. Visit http://www.dovepress.com/ testimonials.php to read real quotes from published authors. 